\title{
Various far-field hydrological responses during 2015 Gorkha earthquake at two distant wells
}

by

\author{
${ }^{1}$ Xudong Huang \\ ${ }^{1,2}$ Yu Zhang \\ 1School of Geodesy and Geomatics \\ Wuhan University \\ Wuhan, 430079, China \\ 2Key Laboratory of Geospace Environment and Geodesy \\ Ministry of Education \\ Wuhan, 430079, China
}

Corresponding Author:

*Yu Zhang (yuz124@gmail.com or yuzhang@sgg.whu.edu.cn)

Submitted for consideration of publication in

Earth, Planet and Space

July 12,2020 


\begin{abstract}
Aquifer hydraulic parameter can change during earthquakes. Continuous monitoring of the response of water level to seismic waves or solid Earth tides provides an opportunity to document how earthquakes influence hydrological properties. Here we use data of two groundwater wells, Dian-22 (D22) and Lijiang (LJ) well, in southeast Tibet Plateau in response to the $2015 \mathrm{Mw} 7.8$ Gorkha earthquake to illustrate hydrological implications. The coherences of water level and seismic wave before and after the far-field earthquake show systematic variations, which may confirm the coseismic dynamic shaking influence at high frequencies $(f>$ $8 \mathrm{cpd}$ ). The tidal response of water levels in these wells shows abrupt coseismic increases of both phase shift and amplitude ratio after the earthquake, which may be interpreted as an increase in the horizontal permeability of a confined aquifer in D22 well, and an occurrence in the vertical permeability of a switched semiconfined aquifer with larger epicentral distance and but high seismic ground motion. Using the continuous transmissivity monitoring, we show that the possible preseismic initial for $\sim 1$ day, coseismic response for $\sim 3$ days and postseismic healing for $\sim 10$ days during the earthquake. Thus, the dynamic shaking during the Gorkha earthquake may have caused confined aquifers to semiconfined aquifers by reopening of preexisting vertical fractures and later healing at epicentral distances about $1500 \mathrm{~km}$.
\end{abstract}

Key word: earthquake, water level, coherence, tidal response, transmissivity 


\section{Introduction}

It has been widely reported that earthquakes can cause various hydrological responses, such as changes in groundwater level (Roeloffs, 1998; Brodsky et al., 2003), increases in stream flow (Muir-Wood and King, 1993; Manga, 2001; Wang et al., 2004a; Wang and Manga, 2015), watertemperature variations (Mogiet al., 1989; Shi et al., 2007; Wang et al., 2013; Shi and Wang, 2014; Zeng et al., 2014; Ma, 2015) and chemical composition (Claesson et al., 2004; Skelton et al., 2014; Zeng et al., 2014), which are always interpreted by induced underground water transport (e.g., Claesson et al., 2007; Wang et al., 2013). Different mechanisms have been proposed to explain these coseismic transport enhancement, including changes in aquifer permeability or storativity (Rojstaczer et al.,1995; Wang et al., 2004a; Manga et al., 2012), static stress and dynamic stress induced pore pressure diffusion (Muir-Wood and King, 1993; Jonsson et al.,2003), consolidation/liquefaction of saturated sediments (Manga, 2001; Manga et al., 2003), rupturing and unclogging of fractures (Sibson and Rowland, 2003 Wang et al., 2004b), and water recharge tank (Kagabua et al., 2020). In phenomenological analysis of this underground flow, the coseismic change in permeability always can be adopted, which also usually attaches to horizontal flow in observation wells (Elkhoury et al., 2006; Xue et al., 2013; Shi et al., 2015) since permeability of a layered groundwater system in the horizontal directionis normally larger than that in the vertical direction (Liao et al., 2015). Recent studies show that near field and intermediate earthquakes may also breach the hydraulic barriers between aquifers and increase vertical permeability (Wang et al., 2004a; Shi and Wang, 2014; Shi and Wang, 2016; Wang et al., 2018; Zhang et al., 2019) that can explain some unexpected aquifer hydrological responses at near field observation. 
Groundwater level monitoring plays an important part in the earthquake prediction program in China, and a nationwide groundwater monitoring well network has been constructed for this purpose (Shi et al., 2015b). In this work, we examine the water level responses at the Dian-22 (D22) and LijiangJ (LJ) wells at southeast margin of Tibet Plateau due to the $2015 \mathrm{Mw} 7.8 \mathrm{Nepal}$ Gorkha earthquake (Figure 1). The distant earthquake ( $>1000 \mathrm{~km}$ ) induced distinct coseismic water-level responses in these two adjacent wells at successive time. The D22 well may be caused by a large coseismic increase in the horizontal permeability; the other LJ well may be caused by a coseismic aquifer leakage switch, i.e., a seismic wave induced vertical diffusion by vertical permeability enhancement in this far field. We interpret the earthquake-induced changes using different moving window coherence with regards to seismic and atmospheric excitations to identify the time dependent hydrological responses in preseismic, coseimic and postseismic phases. Thus, the tidal responses of groundwater in these wells are interpreted by a horizontal flow and a vertical drainage in different time. Furthermore, we interpret the responses in terms of preexist factures unclogging and reclogging by seismic shaking during the earthquake and show that the local site amplification may favor effect on shallow hydrological systems at epicentral distances $>1000 \mathrm{~km}$.

\section{Observations and data}

The April 2015 Nepal Gorkha earthquake occurred at Main Himalayan thrust (MHT) for $\sim 140 \mathrm{~km}$ east-west and $\sim 50 \mathrm{~km}$ across strike and $80 \mathrm{~km}$ WNW of Kathmandu, with a hypocentral depth of $\sim 15 \mathrm{~km}$, the focal mechanism indicating thrusting on a sub-horizontal fault dipping at $\sim 10^{\circ}$ north, which nucleated approximating to the brittle-ductile transition and propagated east along the MHT but did not rupture to the surface (see Figure 1; Avouac et al., 2015; Elliott et al., 2016). 
We have collected the water level data from two distant wells with distinct coseismic responses to the earthquake located in the south boundary of the Tibet Plateau (also see Figure 1). The D22 well is located near the center of Luxi Basin. According to drilling data, the well with $200.17 \mathrm{~m}$ depth is cased with pipe to $95.57 \mathrm{~m}$, with a screened interval between 95.57 and $200.17 \mathrm{~m}$. It is drilled with a diameter of $168 \mathrm{~mm}$ to $6.1 \mathrm{~m}$, and with a diameter of $146 \mathrm{~mm}$ from $6.1 \mathrm{~m}$ to $56.84 \mathrm{~m}$. The diameter between $56.84 \mathrm{~m}$ to $95.57 \mathrm{~m}$ is $127 \mathrm{~mm}$, and at more deeper levels the well has no casing (see details in Figure 2a and Table 1). The LJ well be situated at the north end of Honghe $(\mathrm{HH})$ fault zone. The intersection of Lijiang-Jianchuan (LJ-JS) fault and Zhongdian-Dali (ZD-DL) fault (Feng et al., 2004). The well is drilled to $310 \mathrm{~m}$ and cased with pipe to $240 \mathrm{~m}$, with a screened interval between 240 and $310 \mathrm{~m}$. Within $20 \mathrm{~m}$ depth, the well diameter is $194 \mathrm{~mm}$. And the diameter reduces to $166 \mathrm{~mm}$ at the depth of $80 \mathrm{~m}$. At depth of $80-$ $240 \mathrm{~m}$ the well diameter is $127 \mathrm{~mm}$. The rest part of the well has the diameter of $108 \mathrm{~mm}$ (see details in Figure 2b and Table 1).

The water level is measured by an LN-3A digital water-level gauge (Institute of Seismic Science, China Earthquake Administration). It converts the reading of the digital pressure measurement into the groundwater level. The sampling is $1 \mathrm{~min}$ with the resolution of $1 \mathrm{~mm}$, and the absolute accuracy is $0.2 \%$. The along well seismic waves are recorded by the CTS- 1 broadband seismometer with sampling of $0.01 \mathrm{~s}$. Seismic-wave and water-level data collected from April 14 to May 92015 are analyzed.

\section{Coseismic response identifications}

Preseismic, coseismic and postseismic water-level changes caused by the Gorkha earthquake are clearly identified in the seismic wave and water level data (Figures 3 and 4). The water-level responses show oscillations with sustained postseismic variation. We calculate the 
difference between the levels within $3 \mathrm{~h}$ after the origin time of the Gorkha earthquake to get the amplitude of the oscillation in each well (Ma and Huang, 2017). The amplitudes of the coseismic water level changes are shown in Table 1 and Figures 1. The approximate durations of the coseismic water level changes (the recovery times) are also measured by when the water level decreases down to $5 \%$ of the maximum coseismic response.

Compared the seismic wave (Figure 3) with the water level (Figure 4), it is easy to distinguish the coseismic water level response to the Gorkha earthquake in the D22 well and LJ well by $0.76 \mathrm{~m}$ and $0.16 \mathrm{~m}$ respectively. The durration times of the coseismic water-level changes are $109 \mathrm{~min}$ and $97 \mathrm{~min}$. By exact checking the seismic-wave and water-level time windows, we can discover that the coseismic water-level response mainly corresponds to the Rayleigh surface-wave arrival times. These results suggest that the amplitudes and durations of the coseismic water-level changes were associated with teleseismic surface-wave oscillations.

\subsection{Coseismic coherency analysis}

To estimate how the seismic wave influences the water level, we first calculated the cross ordinary coherence functions $\gamma_{x y}^{2}$ among the water level, vertical displacement seismograms and barometric pressure for each station (Lai, et al., 2013). The ordinary coherence function is defined as

$$
\gamma_{x y}^{2}=\frac{\left|G_{x y}(\omega)\right|^{2}}{G_{x x}(\omega) G_{y y}(\omega)}
$$

where $G_{x x}(\omega)$ and $G_{y y}(\omega)$ are the power spectra of two signals respectively, and $G_{x y}(\omega)$ is the cross-power spectrum between them.

In the calculation, we use the data of each three days around the earthquake from April 23, 2015 to April 28, 2015. These data are continuous and stable. The time window and moving 
window are 1024 min and 512 min, respectively. We calculate the coherence before, around and after the earthquake origin time (Figures 5 and 6). Previous studies show that the barometric pressure and Earth tide are two persistent factors affecting the water level change (e.g., Lai et al., 2013). And the great transfer efficiency of diurnal tide for water level locates around 0.5 - $8 \mathrm{cpd}$. In the low-frequency band $(f<0.5 \mathrm{cpd})$, the barometric pressure also shows the great transfer efficiency for most wells whose ordinary coherence functions are up to 0.9. In the highfrequency band $(f>8 \mathrm{cpd}$ ), both efficiencies for water level decrease though (Lai, et al., 2013). However, in the D22 well, we can observe the high efficiencies for barometric pressure, which may be caused by the in-well barometer. The coseismic shaking broke this high coherence in this high-frequency band (Figure 5c second panel), while the water level response to displacement shows the coherence enhancement between the preseismic and postseismic stages (see Figures 5a, second panel). At the postseismic stage, the low frequency $(f<8 \mathrm{cpd})$ transfer efficiencies increments (up to 0.7 ) of diurnal tide for water level and barometric pressure can be estimated by the high coherences between displacement and water level, as well as displacement and barometric pressure (Figures 5a and 5b, second and third panels), which may mean the more inphase responses of the diurnal tides and post seismic hydrological recoveries. In the LJ well, we can observe the similar water level in response to the displacement excited by the seismic waves at different stages (Figure 6a). The barometric pressure transfer efficiencies did not show obvious cosesimic change as mainly affected in the $0.5-8 \mathrm{cpd}$ as previous mentioned (Lai et al., 2013). It is noted that the coherence between the displacement and barometric pressure shew the similar coseismic decrease in the high frequency band $(f>8 \mathrm{cpd})$ as the that between the water level and barometric pressure in the D22 well (comparing Figures 5c and 6b). An open well barometric pressure observation may make this correspondence. In short, the Gorkha earthquake 
coseismic responses directly shaked in high frequency band $(f>8 \mathrm{cpd})$, and further switched the low frequency diurnal tide transfer efficiencies $(0.5-8 \mathrm{cpd})$, which further illustrate far field the hydrological responses to the great earthquake.

\subsection{Aquifer tidal response analysis}

The tidal responses are stable at semi-diurnal period, but scatter at diurnal frequencies, which may be owing to the diurnal tides being disturbed by resonances induced by the free core nutation, thermal effect and seismic waves (Doan et al. 2006; Lai et al., 2013). Among the tidal constituents, $\mathrm{O} 1$ and M2 tides have large amplitudes and with low barometric effect. Therefore, they are the constituents most widely used in tidal analysis (e.g., Zhang et al., 2016). M2 tide is more popular for its higher accuracy at 12.42 hour period (Hsieh et al., 1987; Rojstaczer and Agnew 1989; Doan et al., 2006), which we use for the following tide analysis.

The amplitude and phase responses of water level to M2 tide can reflect aquifer storativity and permeability around well (Hsieh et al., 1987; Elkhoury et al., 2006; Doan et al., 2006; Xue et al., 2013). In a confined system, high permeability usually causes small phase lags, whereas low permeability results in large phase lags. The amplitude response is primary to measure specific storage (Zhang et al., 2016).

According to Cooper et al. (1965) the steady fluctuation of water level in a well occurs at the same frequency as the harmonic pressure head disturbance in the aquifer which however leads to different amplitude and phase shift. Hsieh et al. (1987) described the pressure head disturbance and water-level response as

$$
\begin{aligned}
h_{f} & =h_{0} \exp (i \omega t), \\
x & =x_{0} \exp (i \omega t),
\end{aligned}
$$


where $h_{f}$ express the fluctuating pressure head in the aquifer. $h_{0}$ is the complex amplitude of the pressure head fluctuation. $x$ is the displacement of the water level from the static position. $x_{0}$ is the complex amplitude of the water-level fluctuation. $t$ indicates time. $\omega=2 \pi / \tau$ is the frequency of fluctuation, where $\tau$ is the period of fluctuation. The ratio between the amplitude of the waterlevel fluctuation and that of the pressure head fluctuation defines the amplitude response $A$ as

$$
A=\left|x_{0} / h_{0}\right|,
$$

The phase shift is defined as

$$
\eta=\arg \left(x_{0} / h_{0}\right),
$$

where $\arg (\mathrm{z})$ is the argument of the complex number $\mathrm{z}$.

M2 tidal signal was decomposed by Bayesian statistics (Tamura et al., 1991). Steps and spikes caused by instrument malfunctions or maintenance work were removed before the analysis. The barometric correction is performed by local barometric data. We use the data from April 14 to May 9 in 2015 when there are no other large earthquakes. 2-day time window is selected to determine the amplitude and phase responses. In Figures 7 and 8, the blue error bars indicate the root-mean-square error (RMSE) of the tidal analysis. The phase shift transient increase caused by the Gorkha earthquake in two wells can be clearly distinguished, whose magnitudes of the coseismic phase shift were greater than 2 times than the RMSE. The phase shifts of the tidal response of the water level increased after the earthquake in both wells consistent to the time dependent coherence analysis. Negative phase before the earthquake that became less negative after the earthquake for the D22 well (from $-22.2^{\circ}$ to $-3.8^{\circ}$ ). While negative phase before the earthquake that became positive after the earthquake for the LJ well (from $37.7^{\circ}$ to $23.8^{\circ}$ ), and restored to negative at the postseismic phase. 


\section{Mechanisms for the water level variations during the earthquake}

Many studies have applied the tidal response of the water level to study the permeability change of well-aquifer systems (Elkhoury et al., 2006; Xue et al., 2013; Lai et al., 2014; Shi and Wang, 2014; Yan et al., 2014; Shi et al., 2015; Zhang et al., 2019).The most common method used for permeability change estimation from tidal analysis was demonstrated by Hsieh et al. (1987). For a homogeneous, isotropic, laterally extensive, and confined aquifer, the phase shifts between Earth tides and water level are assumed to be caused by the time required for the water

to flow into and out of the well, related the aquifer properties. In this case, the drainage effect of groundwater level is ignored and the resulting phase shift should always be negative due to the time required for water to horizontally flow. Therefore, the increase of phase shift in the negative domain in the D22 well means the increase of transmissivity or permeability (Elkhoury et al., 2006). For the positive phase shifts observed in the LJ well, which means preceding water level to tidal strain, Hsieh's model no longer suffices. Roeloffs (1996) presented another model in which vertical drainage of pore pressure to the water table can cause wave-level change in advance. Figure 8 shows that in the LJ well, the coseismic phase response changes to be positive and restores to be negative gradually in postseimic stage. Thus, these phase responses are a combination of normal phase lag caused by wellbore storage effect (aquifer confined) and coseismic phase lead caused by pore diffusion (aquifer not well confined). These observed phase responses can be considered a measure of permeability for both the horizontal fluid flows (e.g., Lai et al., 2013). 


\subsection{Estimation of the aquifer property changes}

The coseismic phase shift of the D22 well varies in negative domain. Based on Hsieh's horizontal flow model, the transmissivity $T$ of aquifers can be estimated, which is the rate of water transmission through a unit width of aquifer under a unit hydraulic gradient as

$$
\begin{aligned}
& A=\left(E^{2}+F^{2}\right)^{-1 / 2}, \\
& \eta=-\tan ^{-1}(F / E),
\end{aligned}
$$

where

$$
\begin{gathered}
E \approx 1-\left(\omega r_{c}^{2} 2 T\right) \operatorname{Kei}(\alpha), \\
F \approx\left(\omega r_{c}^{2} / 2 T\right) \operatorname{Kei}(\alpha), \\
\alpha=(\omega S / T)^{-1 / 2} r_{w},
\end{gathered}
$$

$S$ is the dimensionless storage coefficient. Ker and Kei are the zero-order Kelvin functions. $r_{w}$ is the radius of the well, and $r_{c}$ is the inner radius of the casing. $\omega$ is the frequency of the tide. The $r_{w}$ and $r_{c}$ can be gotten from drilling data (Figure 2a). Both $T$ and $S$ can be obtained (Doan et al. 2006). Finally, the horizontal $T_{\mathrm{h}}$ can be estimated in the $\mathrm{D} 22$ well in days around the earthquake (Figure 9). While in the LJ well, a combination of the horizontal fluid flow model and the vertical pore-pressure diffusion model are adopted to describe the time dependent transmissivity behaviors of negative phase shift and positive phase shift. When the pressure spreads to the free surface, the amplitude of the tide disappears (Roeloffs, 1996). At a low frequency, the skin length may exceed the depth of the shielding layer under where to measure the well pressure (Shi and Wang, 2016). The diffusion of pore pressure with a term due to tidal forcing can be written by a vertical flow in the not well confining formation as (Doan et al., 2006)

$$
\begin{gathered}
\mathrm{D} \frac{\partial^{2} p}{\partial z^{2}}+\mathrm{BK}_{\mathrm{u}} \frac{\partial \varepsilon}{\partial t}=\frac{\partial p}{\partial t^{\prime}} \\
\mathrm{p}(z \rightarrow \infty)=\mathrm{BK}_{\mathrm{u}},
\end{gathered}
$$




$$
p(z=0)=0,
$$

where the solution can be written as

$$
\mathrm{p}(\mathrm{z}, \omega)=\mathrm{BK}_{\mathrm{u}} \varepsilon\left(1-e^{-(1+i) z / \sqrt{2 D / \omega}}\right)
$$

representing the pore-pressure fluctuation at depth $z . B$ is Skempton's coefficient. $K_{u}$ is the bulk modulus of the saturated rock under undrained conditions. $\varepsilon$ is the change in the volumetric strain. $D$ is the hydraulic diffusivity. With the relation $T=D / S$, we can also obtain the vertical transmissivity $T_{\mathrm{v}}$.

\section{Discussion and conclusions}

For the D22 well, the abovementioned negative phase shift (Figure 7) indicates the horizontal groundwater flow in a confined well-aquifer system. We can infer that the Gorkha earthquake had little influence on aquifer confinement changes at the D22 well. The D22 well remained well confined during the earthquake. The horizontal permeability was enhanced by the earthquake. The relationship between transmissivity and permeability is (Elkhoury et al. 2006)

$$
k=\frac{\mu}{\rho g d} T
$$

where $k$ is the permeability, $\mu$ is the dynamic viscosity, $\rho$ is the density, $g$ is the gravitational acceleration and $d$ is aquifer thickness. By the continuous monitor of the horizontal transmissivity $\left(T_{\mathrm{h}}\right)$, the distinct enhancement can last 3 days from coseismic phase to postseismic phase (see Figure 9). The total recovery to the pre-seismic state happened 10 days after the earthquake.

For the LJ well, the coseismic positive phase shift from the negative phase indicates vertical diffusion in a semiconfined well-aquifer system during the earthquake. It is indicated that the well-aquifer system was well confined before The Gorkha earthquake, but became semiconfined 
after the earthquake. These shifts recovered at the 3rd day after the earthquake. This switch may have been caused by a reopening of vertical fractures (Liao et al., 2015), which will reseal over time (Figure 8). The change of aquifer type lasted 2 days. The 3-day sufficient permeability enhancement after earthquake was also observed in the continuous transmissivity measurement (Figure 10). It is noted that the first 2 days change represented the vertical reopening, and the successive meant the covariant change in horizontal aquifer. The recovery to the pre-seismic state also lasted about 10 days after the earthquake.

The enhancement of the transmissivity and hydraulic diffusivity following The Gorkha earthquake may have been caused by the unclogging of preexisting fractures due to the shaking of seismic waves. Many studies have documented these earthquake-induced enhancements in the near field (epicentral distance $<1$ rupture length) and far field (Rojstaczer et al., 1995; Manga and Rowland, 2009; Manga et al., 2012; Shi and Wang, 2014; Wang and Manga, 2015; Shi and Wang, 2016; Wang et al., 2018). The postseismic healing or reclogging of fractures permeability will restore permeability (Xue et al., 2013; Shi and Wang, 2015). The epicentral distances the Gorkha earthquake of the two wells are similar in far field (about 10 times rupture length $\sim 1500$ $\mathrm{km}$, see Table 1). Using the empirical seismic energy estimation as (Wang, 2007)

$$
\log (r)=0.48 M-0.33 \log e(r)-1.4
$$

where $r$ is the actual epicentral distance in kilometers, $M$ is the earthquake magnitude, and $e$ is the seismic energy density (in $\mathrm{Jm}^{-3}$ ). The seismic energy density at the D22 well was $3.4 \times 10^{-3}$ $\mathrm{Jm}^{-3}$, while at the $\mathrm{LJ}$ well was $2.8 \times 10^{-3} \mathrm{Jm}^{-3}$, using this relation derived in southern California, which were not consistent to the peak ground velocity (PGV) estimated from the seismograms (Figure 3). The PGV at the D22 is two orders of magnitude greater. However, the epicenter distance of the LJ well is longer (1530.9 km), and coseismic water-level response magnitude and 
duration is shorter (Figure 1 and Table 1). We also calculate the static strain caused by the Gorkha earthquake based on the Okada model (Lin and Stein, 2004; Toda et al., 2005; Zhang et al., 2017), which turns out to be about magnitude of $10^{-12}$ (positive for dilatation). It is too low to cause water level rise, indicating that the effects of static strain on the coseismic water level change in the far field are negligible, and the water level changes can only be caused by dynamic strain induced by the seismic waves. We infer that the local site amplification effect may make these abnormal seismic responses, which may further differ the hydrological responses. The main aquifer lithology of the LJ well is dolomitic limestone, that is more suitable for fracture development than the marl stone in the D22 well (Mavko et al., 2007). Under the rough estimation of seismic energy at the two wells, about $10^{-3} \mathrm{Jm}^{-3}$ is capable of triggering different kinds of hydrological responses (Wang and Manga, 2010). Therefore, it is reasonable to deduce that the vertical fracture became active and healing that make the vertical permeability increased and restored during the Gorkha earthquake at the LJ well in far field. No aquifer-type change occurred at the same time at the D22 well, and the aquifer parameter (transmissivity and hydraulic diffusivity) changes may reflect unclogging by the seismic wave induced mobilization of colloidal particles and reclogging of preexisting flow pathways.

Comparing Figures 9 and 10, we can see instant healing process during about 10 day period after the Gorkha earthquake. At the D22 well, the horizontal transmissivity changed from $0.1 \times 10^{-4} \mathrm{~m}^{2} / \mathrm{d}$ to $1.5 \times 10^{-5} \mathrm{~m}^{2} / \mathrm{d}$ after the earthquake and decreased further to $0.1 \times 10^{-4}$ $\mathrm{m}^{2} / \mathrm{d}$. Aquifer-type changes induced by the earthquake in the LJ well only lasted two days. The switched vertical transmissivity changed from $3.2 \times 10^{-5} \mathrm{~m}^{2} / \mathrm{d}$ to $5.7 \times 10^{-5} \mathrm{~m}^{2} / \mathrm{d}$, but rechanged to horizontal transmissivity as $7.3 \times 10^{-5} \mathrm{~m}^{2} / \mathrm{d}$ and had recovered to $0.3 \times 10^{-5}$ $\mathrm{m}^{2} / \mathrm{d}$ as the preseismic stage. These decreases may have been caused by the blocking of 
preexisting fractures induced by the Gorkha earthquake, indicating that the local hydrogeological conditions (e.g., permeability, aquifer lithology, and fracture aperture) are important to the recovery process.

The coherence of water level and seismic wave indicated that the coseismic hydrogeological responses were induced by high frequency $(f>8 \mathrm{cpd})$ ground oscillations which means the high dynamic seismic energy. We also can observe more correlation between the water level and seismic wave before the Gorkha earthquake than at the postseismic phase. It may be caused by the tidal response variation in water transmission and solid ground, which, however, also indicated several precursor effects representing in cooperated hydrogeological and solid earth response, which may be preseismic quasistatic strain initial of the earthquake. We may also observe some phase response changes one day before the Gorkha earthquake. The precursor effects in horizontal transmissivity may only be distinguished in the LJ well in April 4. (Figure $10)$.

The wells are distant (about $1500 \mathrm{~km}$ ) to the epicenter, and they are all affected by the Tibet plateau geological evolution. The series far-field hydrogeological responses, especially a coseismic aquifer-type change from confined to semiconfined, may be considered as a significant factor in earthquake fluid monitoring in the seismic active area to great earthquakes.

\section{Availability of data and materials}

The data used in this study can be applied from the National Earthquake Data Center of the China Earthquake Administration (http://earthquake.cn/).

\section{Competing interests}

The authors declare that they have no competing interests. 


\section{Funding}

This research is financially supported by the National Natural Science Foundation of China (NSFC), under Grant No. 41774119) and the special Fundamental Research Funds for the Central Universities (2042017kf0228).

\section{Authors' contributions}

$\mathrm{XH}$ and $\mathrm{YZ}$ carried out most of geologic investigation, data collection, and data pre-treatment. $\mathrm{XH}$ finished the calculation and analysis of coherence and tidal responses and calculated the transmissivities. YZ finished the coseismic hydrological analysis. XH and YZ conceived and coordinated the study, drafted and approved the manuscript.

\section{Acknowledgments}

We thank the China Earthquake Administration for providing the data used in this study. 


\section{Reference}

Avouac, J.-P., Meng L., Wei S., Wang W., Ampuerao J.-P. (2015) Unzipping of the lower edge of the locked Main Himalayan Thrust during the 2015, Mw 7.8 Gorkha earthquake. Nat. Geosci. http://dx.doi.org/10.1038/NGEO2518.

Brodsky, E. E., Roeloffs E., Woodcock D., Gall I., Manga M. (2003), A mechanism for sustained groundwater pressure changes induced by distant earthquakes, J. Geophys. Res., 108(B8), 2390, doi:10.1029/2002JB002321.

Cooper, H.H., Bredhoeft J.D., Papdopulos I.S., Bennnett R.R. (1965) The response of wellaquifer systems to seismic waves. J Geophys Res 70: 3915-3926

Claesson, L., Skelton A., Graham C., Dietl C., Mörth M., Torssander P., Kockum I. (2004) Hydrogeochemical changes before and after a major earthquake, Geology, 32(8), 641-644.

Claesson, L., Skelton A., Grahem C., Mörth C.-M. (2007) The timescale and mechanism of fault sealing and water-rock interaction after an earthquake, Geofluids, 7, 427-440, doi:10.1111/j.1468-8123.2007.00197.x.

Deng, Q., Zhang P., Ran Y. (2006) Distribution of active faults in China (1:4000000). Science Press, Beijing

Doan, M.L., Brodsky E.E., Prioul R., Signer C. (2006) Tidal analysis of borehole pressure-a tutorial. Schlumberger Research Report

Elliott, J.R., Jolivet, R., Gonzalez, P.J., Avouac, J.-P., Hollingsworth, J.C., Searle, M.P., Stevens, V.L., (2016) Geometry of the Main Himalayan Thrust fault revealed by the Gorkha earthquake. Nat. Geosci. http://dx.doi.org/10.1038/NGEO2623

Elkhoury, J.E., Brodsky E.E., Agnew D.C. (2006) Seismic waves increase permeability. Nature 411:1135-1138 
Feng, W. P. et al. (2004) 'Analysis of the characteristic about the Honghe active fault zone based on the ETM+ remote sensing images', in International Geoscience and Remote Sensing Symposium (IGARSS). doi: 10.1109/igarss.2004.1370323.

Hsieh, P.A., Bredehoeft J.D., Farr J.M. (1987) Determination of aquifer transmissivity from earth tide analysis. Water Resour Res 23(10):1824-1832

Jonsson, S., Segall P., Pedersen R., Bjornsson G. (2003) Postearthquake ground movements correlated to pore-pressure transients, Nature, 424, 179-183, doi:10.1038/nature01776.

Kagabua, M., Ideb, K., Hosonoc, T., Nakagawaa, K., Shimadac, J., 2020. Describing coseismic groundwater level rise using tank model in volcanic aquifers, Kumamoto, southern Japan, J. Hydrology, 582, 124464.

Lai G., Huang F., Ge H. (2011) Apparent permeability variation of under- ground water aquifer induced by an earthquake: a case of the Zhouzhi well and the 2008 Wenchuan earthquake. Earthq Sci 24, 437-445.

Lai, G., Ge, H. and Wang, W. (2013) 'Transfer functions of the well-aquifer systems response to atmospheric loading and Earth tide from low to high-frequency band', Journal of Geophysical Research: Solid Earth, 118(5), pp. 1904-1924. doi: 10.1002/jgrb.50165.

Lai, G., Ge H., Xue L., Brodsky E. E., Huang F., and Wang W. (2014) Tidal response variation and recovery following the Wenchuan earthquake from water level data of multiple wells in the near field, Tectonophysics, 619-620, 115-122.

Liao, X., Wang C. Y., Liu C. P. (2015) Disruption of groundwater systems by earthquakes, Geophys. Res. Lett., 42, 9758-9763. 
Lin, J., Stein, R.S., (2004) Stress triggering in thrust and subduction earthquakes and stress interaction between the southern San Andreas and nearby thrust and strike slip faults. J. Geophys. Res. 109, B02303.

Marine, I. W. (1975) Water level fluctuations due to earth tides in a well pumping from slightly fractured crystalline rock, Water Resources Research, 11, doi: 10.1029/WR011i001p00165.

Ma, Y., (2015) Earthquake-related temperature changes in two neighboring hot springs at Xiangcheng, China. Geofluids, 16, 434-439.

Manga, M. (2001) Origin of post-seismic streamflow changes inferred from baseflow recession and magnitude-distance relation, Geophys.Res. Lett., 28, 2133-2136, doi:10.1029/2000GL012481.

Manga, M., Brodsky E. E., Boone M. (2003) Response of streamflow to multiple earthquakes and implications for the origin of postseismic discharge changes, Geophys. Res. Lett., 30, 1214, doi:10.1029/2002GL016618.

Manga, M., Rowland J. C., (2009) Response of Alum Rock springs to the October 30, 2007 Alum Rock earthquake and implications for the origin of increased discharge after earthquakes, Geofluids, 9(3), 237-250.

Manga, M., Beresnev I., Brodsky E. E., Elkhoury J. E., Elsworth D., Ingebritsen S. E., Mays D. C., Wang C. Y. (2012) Changes in permeability caused by transient stresses: Field observations, experiments, and mechanisms, Rev. Geophys., 50, RG2004, doi:10.1029/2011RG00038.

Ma, Y., Huang, F. (2017) 'Coseismic water level changes induced by two distant earthquakes in multiple wells of the Chinese mainland', Tectonophysics, 694(5), 57-68. doi: 10.1016/j.tecto.2016.11.040. 
Mogi, K., Mochizuki, H., Kurokawa, Y. (1989) Temperature changes in an artesian spring at Usami in the Izu Peninsula (Japan) and their relation to earthquakes. Tectonophysics, 159(1), $95-108$.

Muir-Wood, R., King G. C. P., (1993) Hydrological signatures of earthquake strain, J. Geophys. Res., 98, 22035-22068, doi:10.1029/93JB02219.

Rojstaczer, S., Wolf S., Michel R. (1995) Permeability enhancement in the shallow crust as a cause of earthquake-induced hydrological changes, Nature, 373, 237-239.

Roeloffs, E. A. (1996) Poroelastic techniques in the study of earthquakes-related hydrologic phenomena. Adv Geophys 37(1):135-195

Roeloffs, E. A. (1998) Persistent water level changes in a well near Parkfield, California, due to local and distant earthquakes, J. Geophys. Res., 103, 869-889, doi:10.1029/97JB02335.

Shi, Z., Wang G. (2014) Hydrological response to multiple large distant earthquakes in the Mile well, China. J. Geophys. Res. Earth Surf. 11, 2448-2459.

Shi, Y.L., Cao, J.L., Ma, L., (2007) Tele-seismic coseismic well temperature changes and their interpretation. Acta Seismologica Sinica 29 (3), 265-273.

Shi, Z., Wang G., Manga M., Wang C.-Y. (2015b) Mechanism of coseismic water level change following four great earthquakes - Insights from coseismic responses throughout the Chinese mainland, Earth Planet. Sci. Lett., 430, 66-74.

Shi, Z., Wang G., Manga M., Wang C.-Y. (2015) Mechanism of co-seismic water level change following four great earthquakes - Insights from co-seismic responses throughout the Chinese mainland, Earth Planet. Sci. Lett., 430, 66-74.

Shi, Z., Wang G. (2016) Aquifers switched from confined to semiconfined by earthquakes, Geophys. Res. Lett., 43,11,166-11,172, doi:10.1002/2016GL070937. 
Sibson, R. H., Rowland J. V. (2003) Stress, fluid pressure and structural permeability in seismogenic crust, North Island, New Zealand, Geophys. J. Intl., 154, 584-594, doi:10.1046/j.1365-246X.2003.01965.x.

Skelton, A., Andrén, M., Kristmannsdóttir, H. et al. (2014) Changes in groundwater chemistry before two consecutive earthquakes in Iceland, Nat. Geosci., 7, 752-756.

Sun, X., Wang, G., Yang, X. (2015) 'Coseismic response of water level in Changping well, China, to the Mw 9.0 Tohoku earthquake', Journal of Hydrology, 531, 1028-1039.

Shi, Z., Wang G., Wang C.-Y., Manga M., Liu C. (2014) Comparison of hydrological responses to the Wenchuan and Lushan earthquakes, Earth Planet. Sci. Lett., 391, 193-200.

Shi, Z., Wang G. (2014) Hydrological response to multiple large distant earthquakes in the Mile well, China, J. Geophys. Res. Earth Surf., 119, 2448-2459.

Shi, Z., Wang G. (2015) Sustained groundwater level changes and permeability variation in a fault zone following the 12 May 2008, Mw 7.9 Wenchuan earthquake, Hyrol. Processes, 29(12), 2659-2667.

Tamura, Y., Sato T., Ooe M., Ishiguro M. (1991) A procedure for tidal analysis with a Bayesian information criterion, Geophysical Journal International, 104(3), 507-516.

Toda, S., Stein, R.S., Richards-Dinger, K., et al. (2005) Forecasting the evolution of seismicity in southern California: animations built on earthquake stress transfer. J. Geophys. Res.110, B05S16.

Wang, C.-Y. (2007) Liquefaction beyond the near field, Seismol. Res. Lett., 78, 512-517.

Wang, C.-Y., Manga M. (2015) New streams and springs after the 2014 Mw6. 0 South Napa earthquake, Nat. Commun., 6, 7597, doi:10.1038/ncomms8597. 
Wang, C.-Y., Wang C.-H., Manga M. (2004a) Coseismic release of water from mountains:

Evidence from the $1999(\mathrm{Mw}=7.5)$ Chi-Chi,Taiwan, earthquake, Geology, 32, 769-772, doi:10.1130/G20753.1.

Wang, C.-Y., Manga M., Dreger D., Wong A. (2004b) Streamflow increase due to rupturing of hydrothermal reservoirs: Evidence from the 2003 San Simeon earthquake, California, earthquake, Geophys. Res. Lett., 31, L10502, doi:10.1029/2004GL020124.

Wang, C.-Y. (2007) Liquefaction beyond the near field, Seismol. Res. Lett., 78, 512-517.

Wang, C.-Y., Wang L.-P., Manga M., Wang C.-H., Chen C.-H. (2013) Basin-scale transport of heat and fluid induced by earthquakes, Geophys. Res. Lett., 40, 3893-3897, doi:10.1002/grl.50738

Wang, C.-Y., Manga M. (2015) New streams and springs after the 2014 M6.0 South Napa earthquake, Nat. Commun., 6, 7597.

Wang, C.-Y., Doan M.-L., Xue L., Barbour, A. J. (2018) Tidal response of groundwater in a leaky aquifer-Application to Oklahoma. Water Resources Research, 54, 8019-8033.

Xue, L., Li H.-B., Brodsky E. E., Xu Z.-Q., Kano Y., Wang H., Mori J. J., Si J.-L., Pei J.-L., Zhang W. (2013) Continuous permeability measurements record healing inside the Wenchuan earthquake fault zone, Science, 340(6140), 1555-1559.

Yan, R., Woith H., Wang R. (2014) Groundwater level changes induced by the 2011 Tohoku earthquake in China mainland, Geophys. J. Int., 199(1), 533-548.

Zhang, Y., Fu L., Ma Y., Hu J. (2016) 'Different hydraulic responses to the 2008 Wenchuan and 2011 Tohoku earthquakes in two adjacent far-field wells: The effect of shales on aquifer lithology 4. Seismology', Earth, Planets and Space, 68, 17, doi: 10.1186/s40623-016-0555-5. 
Zhang, Y., Wang C.-Y., Fu L.-Y., Zhao B., Ma Y., Unexpected far-field hydrological response to a great earthquake, Earth and Planetary Science Letters, 519, 202-212.

Zeng, X., Lin,Y., Chen W., Bai Z., Liu J.Y., Chen, C.H., 2014. Multiple seismo-anomalies associated with the M6.1 Ludian earthquake on August 3, 2014, Journal of Asian Earth Sciences, 114, 352-361. 